\title{
Fault segmentation, paleostress and paleoseismic investigation in the Dodoma Area, Tanzania: implications for seismic hazard evaluation
}

\author{
Athanas Simon Macheyeki \\ Promotoren: Marc De Batist (1), Abdulkarim Mruma (2), \\ Damien Deluaux (3) \\ (I) Department of Geology and Soil Science, Ghent University \\ (2) Department of Geology, University of Dar Es Salaam, Tanzania \\ (3) Royal Museum for Central Africa, Tervuren
}

Public defence: 19 September 2008

The Dodoma area (Tanzania) lies within the Tanzanian craton, in a region where the eastern branch of the East African Rift System seems to die out (or propagate?) into the craton. The area is characterized by low- to moderate-magnitude seismic activity, sometimes concentrated into so-called "earthquake swarms", but also by rare large earthquakes (up to $M w=6.2$ ). On 4 November 2002, an earthquake of $M w$ ffi 5.5 struck the region during a session of the Tanzanian Parliament in Dodoma, causing cracks in the Parliament building. This seismic event raised the awareness of a large proportion of the Tanzanian society on geo-hazards. This research is a response to that awareness.

This works intends i) to identify the faults that are potentially active in the area, ii) to study their orientation and geometry and their degree of segmentation, iii) to conduct a detailed paleostress analysis and analyse the stress-field responsible for the present-day seismic activity, iv) to evaluate the history of fault-slip activity throughout the Holocene, and v) to make an attempt in quantifying the future potential earthquakes in the area.

At least seven active faults were identified in the area and were studied in detail: i.e., the Mponde, Saranda, Bubu, Makanda, Hombolo, Bahi and Fufu faults. The Mponde and the Bahi faults trend NW-SE to N-S, whereas the other five faults generally trend NE-SW. Displacement profiles of these faults and their geometric pattern show that the faults are segmented. The fault segments obtained are: Segment I (3I km) and Segment $2(28 \mathrm{~km})$ for the Mponde fault; Saranda south segment (II km), Saranda mid segment (29 km) and Saranda north segment $(24 \mathrm{~km}$ ) for the Saranda fault; Nkambala segment $(33 \mathrm{~km})$, Makutupora segment ( $30 \mathrm{~km}$ ) and Gonga segment $(42 \mathrm{~km}$ ) for the Bubu fault; Segment $A(\leq 3 \mathrm{rm})$, Segment B (18 km), Segment C ( $15 \mathrm{~km})$ and Segment D (22 km) for the Makanda fault; Nzuguni segment ( $>19 \mathrm{~km}$ ) and Dam segment ( $\geq \mathrm{I} 8 \mathrm{~km}$ ) for the Hombolo fault; Northwestern segment $(\leq 29 \mathrm{~km})$ and Southeastern segment $(\geq 25 \mathrm{~km})$ for the Bahi fault, Segment A (6 km), Segment B $(25 \mathrm{~km})$, Segment C (3I km) and Segment D $(\geq 5)$ for the Fufu fault. The length of each segment reflects the earthquake potential for that given segment. Studies of fault segments deduced from displacement profiles show that the segments in the Dodoma area can generate relatively large earthquakes in the order of $M W=6.3$ to 7 . 
The reduced stress tensor for the stress regimes computed from (Late Cenozoic) fault-slip data for distinct segments of the Saranda, Bubu, Nkambala, Bahi, Fufu and Hombolo faults in the Dodoma area show comparable Shmin values that are nearly E-W. The present-day stress regime that was computed from focal-mechanism data in the larger region of the "Manyara-Dodoma rift" also shows a Shmin direction that is approximately E-W. In addition, newly formed surface fractures also reflect this $\mathrm{E}-\mathrm{W}$ extensional stress field.

Limited paleoseismic data obtained from a trench across the Bubu fault indicates that the most recent large earthquake event along the Bubu fault in the Dodoma area took place in the Middle Holocene (i.e., more recently than 6807-6999 cal. yr BP) and had a vertical offset of about $30 \mathrm{~cm}$, corresponding to a possible magnitude of $\mathrm{Mw}=6.3-6.4$. The time interval between this Middle Holocene event and the preceding large seismic event is about $2200 \mathrm{yr}$, equivalent to an average slip rate of about $0.15 \mathrm{~mm} / \mathrm{yr}$.

All these results imply that the Dodoma area is indeed seismically active and prone to large earthquakes. The risk can be diminished by building structures that take into account earthquake resistant design and by educating people about earthquake safety. However, more paleoseismological researches integrated with other related studies, such as seismology, archeology and geophysics, need to be undertaken in order to better assess and evaluate the seismic risk of the Dodoma area, which is where the fast-growing capital city of Tanzania is located. 